\title{
Study of maternal mortality in a tertiary care hospital in a tribal KBK area of Odisha, India
}

\author{
Sasmita Behuria, Jyoti Narayan Puhan*, Subhra Ghosh, Bhabani Sankar Nayak
}

Department of Obstetrics and Gynaecology, Saheed Laxman Nayak Medical College, Koraput, Odisha, India

Received: 21 November 2019

Accepted: 30 December 2019

*Correspondence:

Dr. Jyoti Narayan Puhan,

E-mail: jyoti.scb87@gmail.com

Copyright: (C) the author(s), publisher and licensee Medip Academy. This is an open-access article distributed under the terms of the Creative Commons Attribution Non-Commercial License, which permits unrestricted non-commercial use, distribution, and reproduction in any medium, provided the original work is properly cited.

\begin{abstract}
Background: Pregnancy, although being considered a physiological state, carries risk of serious maternal morbidity and at times death. This is due to various complications that may occur during pregnancy, labor, or thereafter. The major causes of maternal mortality are mostly preventable through regular antenatal check-up, proper diagnosis, and management of labor complications. Therefore, the factors at different levels affecting the use of these services need to be clearly understood. The aim is to study the incidence of MMR, assess the epidemiological aspects, causes of maternal mortality and avoidable factors that can prevent maternal deaths.

Methods: A retrospective hospital-based study was conducted in obstetrics and gynecology department, SLN MCH, a tertiary care referral hospital in a tribal area of southern Odisha over a period of 2 years from April 2017 to March 2019.

Results: A total of 108 deaths were analyzed over 2 years period and MMR was calculated to be 1124/1 lakh live births. Most of the maternal deaths occurred in the age group of 20-24 years (35.1\%), majority of maternal deaths were observed in multipara $(46.3 \%), 70.3 \%$ deaths occurred within 24 hours of admission. Hypertensive disorders in pregnancy $(37 \%)$ were the leading direct cause followed by hemorrhage $(14.8 \%)$ and sepsis $(11.1 \%)$. Among the indirect causes jaundice $(7.4 \%)$ and anaemia (3.7\%) were the leading cause.

Conclusions: MMR in our study was very high as compared to national average of $167 / 1,00,000$ live births, being a tertiary care hospital as most of the patients were referred from peripheral centers. Most maternal deaths are preventable by intensive health education, basic obstetric care for all, strengthening referral and communication system and emphasizing on overall safe motherhood.
\end{abstract}

Keywords: Anaemia, Hypertensive disorder, Maternal mortality ratio

\section{INTRODUCTION}

Maternal mortality is defined as the death of any woman while being pregnant or within 42 completed days of termination of pregnancy, irrespective of the duration or site of pregnancy, from any cause related to or aggravated by pregnancy, but not from accidental or incidental causes. ${ }^{1}$ Maternal Mortality Ratio (MMR) is defined internationally as the maternal mortality rate per 1 lakh live births. Maternal mortality remains one of the most daunting public health problems in India. Even today
$20 \%$ global maternal deaths occur in India. ${ }^{2}$ MMR for India was 301 per 100,000 live births by Sample Registration Survey (SRS) 2003 estimate and came down to 167 by SRS survey 2013 estimate. $^{3}$

Maternal mortality is ascribed usually to complications that generally occur during or around labor and cannot be accurately predicted. The direct causes of maternal mortality, that is, hemorrhage, unsafe abortion, eclampsia, obstructed labor, infection, and others account for about three-fourths of maternal deaths. The remaining 
one-fourth are indirect causes such as anemia, hepatitis, heart disease, malaria, and Human Immunodeficiency Virus (HIV)/Acquired Immunodeficiency Syndrome (AIDS). The other contributory causes are early marriage, adolescent pregnancy, poverty, malnutrition, harmful traditional practices, illiteracy/ignorance, etc. ${ }^{4}$ These are mostly preventable through regular antenatal check-up, proper diagnosis and management of labor complications.

Maternal mortality is an indicator of the quality of obstetric care in a community, directly reflecting the utilization of health-care services available. ${ }^{6}$ One of the most important goals of the MDGs is to reduce the maternal mortality. It was in this context; this study was conducted with the objectives to assess the existing MMR and the causes of maternal mortality over a period of 2 years in a tertiary care hospital of a tribal area of Southern Odisha.

\section{METHODS}

The present study was a retrospective study conducted in the department of obstetrics and gynecology, Saheed Laxman Nayak Medical College, Koraput, a tertiary care hospital of south Odisha over a period of 2 years from April 2017 to March 2019. This college is situated in a tribal dominated area and receives patients from 4 tribal districts of Odisha i.e. Koraput, Nabarangpur, Rayagada and Malkanagiri. The peoples are mostly tribal, less educated and less reach to health care systems. All booked or unbooked maternal deaths admitted at the time of pregnancy, delivery or during peurperium were included in the study and deaths not related to pregnancy were excluded from the study. The information regarding MMR are collected from various hospital records and also from patient and their relatives after getting permissions from hospital authorities.

\section{Statistical analysis}

Every maternal death was scrutinized and data were collected on a proforma and results were analyzed using percentage and proportion with the help of Microsoft Excel 2007.

\section{RESULTS}

A total of 108 maternal deaths and 9608 live births occurred during 2 years study period from April 2017 to March 2019. The MMR in the study period was 1124 per 1 lakh live births. In the present study, maternal deaths mostly occurred in the age group of 20-24 years i.e. 38 cases $(35.1 \%)$, followed by $25-29$ years age group i.e. 34 cases $(31.5 \%) .14(13 \%)$ cases each in age group 30-34 years and above 34 years and below 20 years 8 (7.4\%) maternal deaths occurred (Figure 1).

Figure 2 shows distribution of maternal deaths according to parity of mothers. Majority of mothers were G3 and above (46.3\%) followed by primipara (38.9\%), only $14.9 \%$ maternal deaths belong to second gravid. Time interval from admission of mother to her death is depicted in Figure 3. $76(70.3 \%)$ maternal deaths occurred within 24 hours of admission in hospital and 28 (26\%) maternal deaths occurred within 1-6 days of admission. Only 4 (3.7\%) deaths happened beyond 7 days of hospital stay.

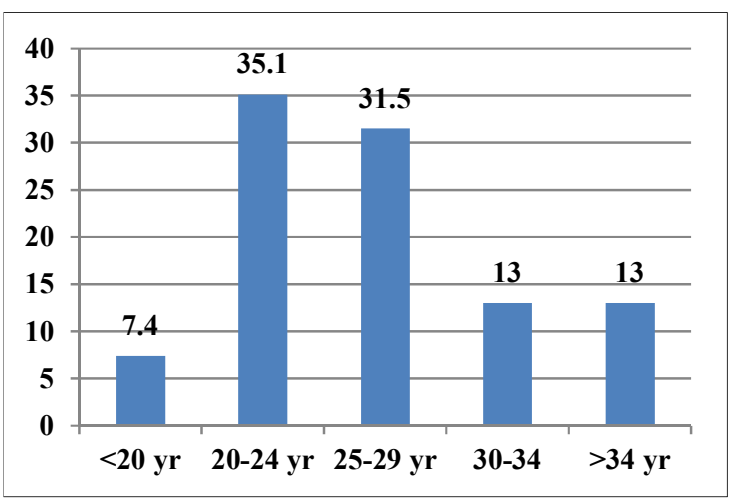

Figure 1: Distribution of maternal deaths according to maternal age.

Table 1: Causes of maternal deaths.

\begin{tabular}{|lll|}
\hline Cause & Frequency & Percentage (\%) \\
\hline Direct causes & & \\
\hline $\begin{array}{l}\text { PIH/pre-eclampsia } \\
\text { /eclampsia }\end{array}$ & 40 & $37 \%$ \\
\hline Haemorrhage & 16 & $14.8 \%$ \\
\hline Sepsis & 12 & $11.1 \%$ \\
\hline APH & 2 & $1.85 \%$ \\
\hline EMBOLISM & 2 & $1.85 \%$ \\
\hline Rupture Uterus & 8 & $7.4 \%$ \\
\hline Rupture ectopic & 2 & $1.85 \%$ \\
\hline Obstructed labour & 2 & $1.85 \%$ \\
\hline IUD with DIC & 4 & $3.7 \%$ \\
\hline Indirect causes & & \\
\hline Anaemia & 4 & $3.7 \%$ \\
\hline Jaundice & 8 & $7.4 \%$ \\
\hline Heart disease & 2 & $1.85 \%$ \\
\hline TB & 2 & $1.85 \%$ \\
\hline Sickle cell crisis & 4 & $3.7 \%$ \\
\hline Total & 108 & $100 \%$ \\
\hline
\end{tabular}

As evident from Table 1, direct causes contributed to $81.5 \%$ maternal deaths and indirect causes contributed to $18.5 \%$ of maternal deaths. Among the direct causes of maternal deaths, majority was due to hypertensive disorders of pregnancy $(40,37 \%)$ followed by haemorrhage $(16,14.8 \%)$, Sepsis $(12,11.1 \%)$, rupture uterus $(8,7.4 \%)$ and IUD with DIC $(4,3.7 \%)$. Jaundice $(8,7.4 \%)$ was the most common indirect cause of maternal death followed by anaemia $(4,3.7 \%)$, sickle cell crisis $(4,3.7 \%)$, TB $(2,1.85 \%)$ and heart disease $(2$, $1.85 \%)$. Out of 108 cases, $18(16.6 \%)$ cases delivered 
vaginally in our hospital and died, 12 (11.1\%) cases died after LSCS and laparotomy done for rupture uterus and ectopic in low condition. Another 28 (26\%) cases, they delivered vaginally in another $\mathrm{PHC}, \mathrm{CHC}, \mathrm{SDH}, \mathrm{DHH}$ and referred to our hospital died. In another $4(3.7 \%)$ cases LSCS was done outside and died in our hospital. 4 (3.7\%) maternal deaths occurred due to home delivery. $42(38.9 \%)$ out of 108 cases did not deliver and died due to eclampsia $(18,16.7 \%)$, rupture uterus $(4,3.7 \%)$, rupture ectopic $(2,1.85 \%)$, jaundice $(4,3.7 \%)$, sickle cell crisis $(4,3.7 \%)$, anaemia $(4,3.7 \%), \mathrm{TB}, \mathrm{APH}$ and obstructed labour $2(1.85 \%)$ each. Almost all died within 24 hours of admission to hospital.

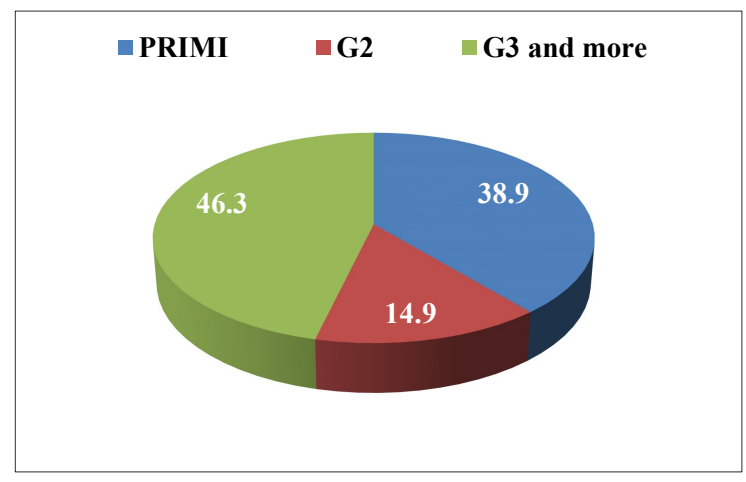

Figure 2: Distribution of maternal deaths according to parity.

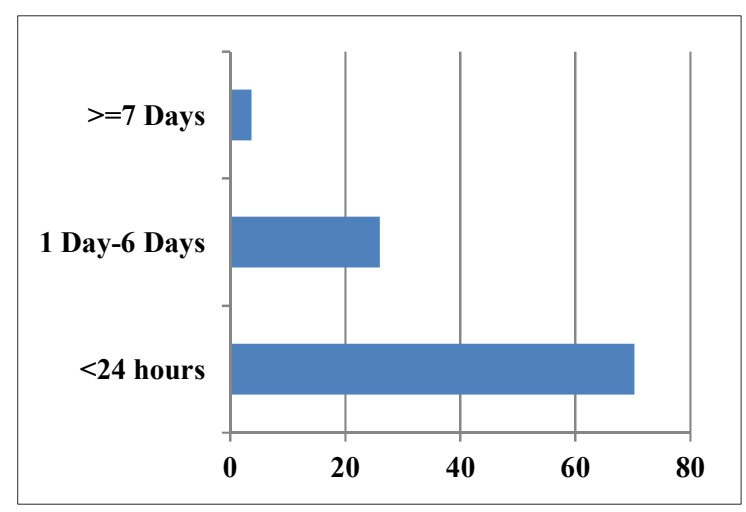

Figure 3: Time interval from admission to maternal death.

\section{DISCUSSION}

Death of mother is a tragic event. In practical life, it has a severe impact on the family, community and eventually, the nation. Reduction of maternal mortality is the objective of MDGs, especially in low-income countries, where 1 in 16 women die of pregnancy-related complications. $^{7}$

In this study, 108 maternal deaths and 9608 live births occurred, leading to 1124 maternal deaths out of 1lakh live births over 2 years. Other studies from tertiary care institutions reported mortality rate of 113 to 879 per 1 lakh live births. ${ }^{8-10}$ The incidence and proportion of complications seen in mothers is probably very different from what occurs in the community because hospital delivery rate is still not up to the mark in this tribal area. At the same time hospital data estimated may be more than community data as high-risk women are referred to hospital for delivery and often the women are only referred to hospital when they develop life threatening complications, which is too late and thus increase the number of hospital deaths. ${ }^{11}$

In this study, majority of maternal deaths (35.1\%) was observed in women of age group 20-24 years followed by $31.5 \%$ in $25-29$ years age group. Similarly, Bangal et al, in their study observed that $55.27 \%$ maternal deaths were in the age group of 19-24 years. ${ }^{12}$ Yerpude et al, in their study showed that the age group in which most $(74.36 \%)$ maternal deaths occurred was 21-30 years group. ${ }^{2}$ This was because the highest number of pregnant women belonged to this group. In our study majority of mothers were multipara $(46.3 \%)$ followed by primipara $(38.9 \%)$. Similarly, $42.10 \%$ were primi-gravidas and $57.89 \%$ were multigravidas in the study by Bangal et al, and $56.41 \%$ were multipara and $35.90 \%$ were primipara in the study by Yerpude et al. ${ }^{2.12}$ Increased number of pregnancies and decreased interval between pregnancies together adversely affect the mother's health and responsible for fatal outcomes.

In this study, $70.3 \%$ maternal deaths occurred within 24 hours of hospital admission and 26\% maternal deaths occurred within 1-6 days of hospital admission. Priya et al, in their study also observed maximum deaths $(54.63 \%)$ within 24 hours of hospital admission. In contrast, $47.20 \%$ maternal deaths were within 1-7 days and $27.07 \%$ were beyond 7 days of hospital admission in the study by Bhosale et al. ${ }^{13,21}$ It becomes apparent that many of the deaths that occurred could have been avoided if they were transferred earlier further highlighting the need for adequate and quick transport facilities.

This study revealed that $81.5 \%$ maternal deaths were due to direct obstetrical causes and $18.5 \%$ due to indirect causes. Other studies have shown variations in direct obstetrical deaths, $68.70 \%$ in a study by Kulkarni et al, and $60 \%$ by Salhan et al. ${ }^{14,15}$ Even today large number of maternal deaths were due to classic triad of hypertension, hemorrhage and sepsis. In this study also $37 \%$ of MMR is due to hypertensive disorders, $14.8 \%$ due to hemorrhage and $11.1 \%$ due to sepsis, leading to $63 \%$ of MMR which is comparable to study done by $\mathrm{Pal}$ et al, and also by Konar et al. ${ }^{16,17}$ Although use of magnesium sulphate and early termination of pregnancy has led to improvement in the scenario of eclampsia, early diagnosis of PIH needs to be emphasized to prevent due to it. The decrease in death due to haemorrhage is mainly attributed to SBA training to all staff nurses and availability of effective oxytocic. The need for antibiotics and infection control practices 
are to be strictly followed to reduce death due to sepsis. ${ }^{18}$ Jaundice $(7.4 \%)$, anaemia $(3.7 \%)$ and heart disease were the leading indirect causes of MMR which is comparable to the study done by $\mathrm{Pal}$ et al. ${ }^{16}$ Being a sickle cell anaemia dominated area, $3.7 \%$ deaths occurred due to sickle cell crisis before term. The tertiary care hospitals regrettably receive usually complicated cases through referral and mostly admitted only during the terminal stage of their illness. This may be the reason for such a high report of MMR in college during the period of April 17 to March 19.

\section{CONCLUSION}

Every pregnancy should culminate in healthy mother and healthy baby and for that we need to ensure that all women should have access to high quality essential and emergency obstetric care along with promotion of overall safe motherhood. The retrospective record-based nature and relatively small sample size collected over 2 years are the limitations of this study. Overall, this study has managed to contribute substantial additional information regarding the causes of maternal mortality in a tertiary care hospital at a tribal dominated population so that timely measures can be taken to prevent such type of incidences in future. Most of maternal deaths are preventable by optimum utilization of existing $\mathrm{MCH}$ facilities, identifying loopholes in health care delivery system, early identification of high-risk pregnancies and their timely referral to higher centre.

\section{ACKNOWLEDGMENTS}

Authors would like to thank colleagues of department of obstetrics and gynecology and clerical staff of medical records department for their support during study.

Funding: No funding sources

Conflict of interest: None declared

Ethical approval: The study was approved by the Institutional Ethics Committee

\section{REFERENCES}

1. Empowering communities to avert maternal deaths in India. Available at: http://www.unicef.org/india/MAPEDIRMaternal_and_perinatal_death_inquiry_and_responseIndia.pdf. Accessed on $12^{\text {th }}$ November 2015 .

2. Yerpude PN, Keerti S Jogdand. A 5-year retrospective study of pattern of maternal mortality in a tertiary care hospital in South India. Int J Recent Trends Sci Technol. 2014;11(3):310-2.

3. Maternal Mortality Ratio (MMR), maternal mortality rate and life time risk; India, EAG and Assam, South and Other states, 2011-13. Available at: http://censusindia.gov.in/vital_statistics/mmr_bulleti n_2011-13.pdf. Accessed on $22^{\text {nd }}$ November 2015 .

4. Wadhwa L, Gupta S, Jain A. Demography and aetiological profile of maternal mortality cases at a tertiary care centre of India - five and a half years retrospective analysis 2013. Indian J Med Specialities. 2013;4(2):238-42.

5. Zaman S, Begum AA. Maternal mortality at a rural medical college of Assam: a retrospective study. J Obstet Gynaecol Barpeta. 2014;1(1):46-51.

6. Mukherjee S, Mukherjee S, Sarkar RR. A six year retrospective study of maternal mortality at a tertiary teaching institute in Uttar Pradesh. Int J Med Sci Public Health. 2014;3(11):1407-9.

7. Gurina NA, Vangen S, Forsen L, Sundby J. Maternal mortality in St. Petersburg, Russian Federation. Bull World Health Organization. 2006;84:283-9.

8. Bedi N, Kambo I, Dhillon BS, Saxena BN, Singh P. Maternal deaths in India: Preventable Tragedies (An ICMR Task Force Study) J Obstet Gynecol Ind. 2001;51:86-92.

9. Purandare N, Singh A, Upadhya S, Sanjanwala SM, Saraogi RM. Maternal mortality at a referral centre: a five-year study. J obstetric Gynaecol India. 2007;57(3):248-50.

10. Kulkarni SR, Huligol A. Maternal mortality-10 year study. J Obstet Gynaecol India. 2001;51(2):73-6.

11. Priya N, Verma A, Verma S. Maternal mortality: ten years retrospective study. JK Sci. 2010;12(3):134-6.

12. Bangal VB, Giri PA, Garg R. Maternal mortality at a tertiary care teaching hospital of rural India: a retrospective study. Int $J$ Biol Med Res. 2011;2(4):1043-6.

13. Bhosale A, Qureshi S, Nandanwar YS. Maternal mortality at a tertiary institute: a five-year study. Bombay Hospital J. 2011;53(2):189-92.

14. Kulkarni S, Athani S, Seetaram S. Maternal mortality of Head Quarter Hospital, Bellary. J Obstet Gynaecol Ind. 1996;46(4):492-6.

15. Salhan S, Sharma M, Suri J. Maternal mortality in a tertiary hospital. JOSH. 2000;7:78-9.

16. Pal A, Ray P, Hazra S, Mondal TK. Review of changing trends in maternal mortality in a rural medical college in West Bengal. Jobstr Gynecol India. 2005:55(6):521-4

17. Konar H, Chakraborty AB. Maternal mortality: a FOGSI study (Based on Institutional Data). J Obst Gynecol. 2013;63(2):88-9.

18. Mohanasundari KP, Padma PR, Subathra. Maternal mortality:analysis of causes and preventable factors. Int J Reprod Contracept Obstet Gynecol. 2016;5(6):1719-21.

Cite this article as: Behuria S, Puhan JN, Ghosh S, Nayak BS. Study of maternal mortality in a tertiary care hospital in a tribal KBK area of Odisha, India. Int J Reprod Contracept Obstet Gynecol 2020;9:1528-31. 